\title{
Defamiliarization: Flarf, conceptual writing, and using flawed software tools as creative partners
}

\author{
Richard P. Gabriel* \\ IBM Research \\ 3636 Altamont Way, Redwood City CA 94062, USA \\ E-mail: rpg@dreamsongs.com; rpg@us.ibm.com \\ *Corresponding author
}

\begin{abstract}
One form of creativity uses defamiliarization, a mechanism that frees the brain from its rational shackles and permits the abducing brain to run free. Mistakes and flaws in several software tools are shown to be the starting points for increased creativity and better art, and a theory explaining the phenomenon is proposed.
\end{abstract}

Keywords: Writing; Poetry; Creativity; Flarf

Biographical notes: Richard P. Gabriel received a PhD in Computer Science from Stanford University in 1981, and an MFA in Poetry from Warren Wilson College in 1998. He has been a researcher at Stanford University, company president and Chief Technical Officer at Lucid, Inc., vice president of Development at ParcPlace-Digitalk, a management consultant for several startups, a Distinguished Engineer at Sun Microsystems, and Consulting Professor of Computer Science at Stanford University. He is an ACM Fellow.

$\mathrm{He}$ is a researcher at IBM Research, looking into the architecture, design, and implementation of extraordinarily large, self-sustaining systems as well as development techniques for building them. Until recently he was President of the Hillside Group, a nonprofit that nurtures the software patterns community by holding conferences, publishing books, and awarding scholarships. He is on Hillside's Board of Directors.

He helped design and implement a variety of dialects of Lisp. He is author of four books ("Performance and Evaluation of Lisp Systems," MIT Press; "Patterns of Software: Tales from the Software Community," Oxford University Press; "Writers' Workshops and the Work of Making Things," Addison-Wesley Press; and "Innovation Happens Elsewhere: Open Source as Business Strategy," Morgan Kaufmann), and a poetry chapbook ("Drive On," Hollyridge Press), with two books of poetry in preparation: "Leaf of my Puzzled Desire" and "Drive On." He has published more than 100 scientific, technical, and semi-popular papers, articles, and essays on computing. He has won several awards, including the AAAI/ACM Allen Newell Award.

$\mathrm{He}$ is the lead guitarist in a rock 'n' roll band and a poet. 


\begin{abstract}
Ark!!!
Shem raised the rope and forced his bulky frame through chapped his knees when they allowed a braying ass through the holy gates but it's holy shit fire downtown

his oiled black hair glistened in the sun as the ass was led around the path toward the pinnacle of the secret of the hiding place of the Holy Ark

Noah bitched and moaned about the count so Yaphet used the pinnacle of a technical split legged capture bomb (holy fuck) this kicked all kinds of ass
\end{abstract}

Ham completely destroyed his bitch ass

A poem like this is easy to dislike.

But it's flarf (Goldsmith, 2009) and I wrote it in 2003 using Google to search for documents mentioning terms not likely to appear together-here "ark," "pinnacle," "ass," and "holy" - and then I worked with some of the returned synopses pasted together as a first draft. The point of working this way isn't to be cute but to assist the mind in finding unfamiliar situations, novel language, unexpected combinations, and therefore new territory to explore and thereby to make new discoveries possible, finally leading (perhaps) to fresh understanding.

I call this defamiliarization; it's not a new technique - in the past we noticed defamiliarization when the artist appeared to have a strong streak of idiosyncratic creativity and we admired the unusual mind operating behind the scenes. My use of this term is not the same as Victor Shklovsky's, who used it to describe the outcome of an artistic process (Shklovsky, 1988). That is, Shklovsky described as defamiliarized those poems or other pieces of writing that used unfamiliar and disquieting language and images to disturb and disrupt the reader in order to make the poem or piece more vivid and to invite the reader to look afresh at the thing(s) described. My use locates defamiliarization in the creative process itself and characterizes it as a mechanism to invite-or more accurately, to force - the artist to explore more deeply and widely in creating the piece.

Exploration is essential to artists; artists thrive on a sort of defocused attention, engaging in flat associations by going broad not deep. This is exploration; by noticing, artists begin to discover. Discovery is making connections, and this is where metaphors pop up. The fiction writer Peter Turchi writes that exploration is "some combination of premeditated searching and undisciplined, perhaps only partly conscious, rambling," and that "if we persist, we discover" (Turchi, 2004).

Exploration is opening the mind to possibilities; discovery can be literal discovery, such as finding a pot of gold at the end of a rainbow, but sometimes it's a guess - this is the best way to structure the story, the best image to convey the narrative or lyrical point, or the best explanation of what you saw while exploring; understanding is coming to 
believe (based on gathered evidence) that the discovery or guess is valid - that it is right, that it is what is needed, and perhaps why it's valid.

Turchi says, "exploration is assertive action in the face of uncertain assumptions, often involving false starts, missteps, and surprises" (Turchi, 2004). Discovery, as William Stafford might say, is a "reckless encounter with whatever comes along" (Stafford, 1987).

Artistic creation is as much about being lost as exploring known-even halfknown - territory. Great explorers don't explore the parts of the map that have names. Turchi sums it up like this:

Artistic creation is a voyage into the unknown. In our own eyes, we are off the map. The excitement of potential discovery is accompanied by anxiety, despair, caution, perhaps, perhaps boldness, and, always, the risk of failure. Failure can take the form of our becoming hopelessly lost, or pointlessly lost, or not finding what we came for (though that last is sometimes happily accompanied by the discovery of something we didn't anticipate, couldn't even imagine before we found it). We strike out for what we believe to be uncharted waters, only to find ourselves sailing in someone else's bathtub. Those are the days it seems there is nothing new to discover but the limitations of our own experience and understanding. (Turchi, 2004)

Many artists - particularly experimental artists (defined below; but it doesn't mean avant-garde) - use a process of creating a first "draft" of the piece and then using that draft as a partner in the creative process. Fiction writer Robert Boswell puts it this way:

I have grown to understand narrative as a form of contemplation, a complex and seemingly incongruous way of thinking. I come to know my stories by writing my way into them. I focus on the characters without trying to attach significance to their actions. I do not look for symbols. For as long as I can, I remain purposefully blind to the machinery of the story and only partially cognizant of the world my story creates. I work from a kind of half-knowledge.

In the drafts that follow, I listen to what has made it to the page. Invariably, things have arrived that I did not invite, and they are often the most interesting things in the story. By refusing to fully know the world, I hope to discover unusual formations in the landscape, and strange desires in the characters. By declining to analyze the story, I hope to keep it open to surprise. Each new draft revises the world but does not explain or define it. I work through many drafts, progressively abandoning the familiar. What I can see is always dwarfed by what I cannot know. What the characters come to understand never surpasses that which they cannot grasp. The world remains half-known.

There can be no discovery in a world where everything is known. A crucial part of the writing endeavor is to practice remaining in the dark. (Boswell, 2008) 
When we think formally about creative acts, the question arises: Where does new stuff come from? The philosopher Charles Sanders Peirce recognized that traditional logical induction and deduction were closed with respect to prior assumptions and data: they cannot produce new ideas. He proposed abduction to explain the form of reasoning that leads to new ideas. Informally, such an inference leads from an observation of a situation that is not yet understood to a hypothesis that, if true, explains the observed phenomenon. Peirce wrote:

Now, that the matter of no new truth can come from induction or from deduction, we have seen. It can only come from abduction; and abduction is, after all, nothing but guessing. We are therefore bound to hope that, although the possible explanations of our facts may be strictly innumerable, yet our mind will be able, in some finite number of guesses, to guess the sole true explanation of them. That we are bound to assume, independently of any evidence that it is true. Animated by that hope, we are to proceed to the construction of a hypothesis. (Hartshorne \& Weiss, 1958)

How are defamiliarization and abduction connected? Consider this experiment: Look at the grammar below. A test subject is shown one at a time 45 strings of length between 6 and 9 characters generated by it, and asked to copy down each one.

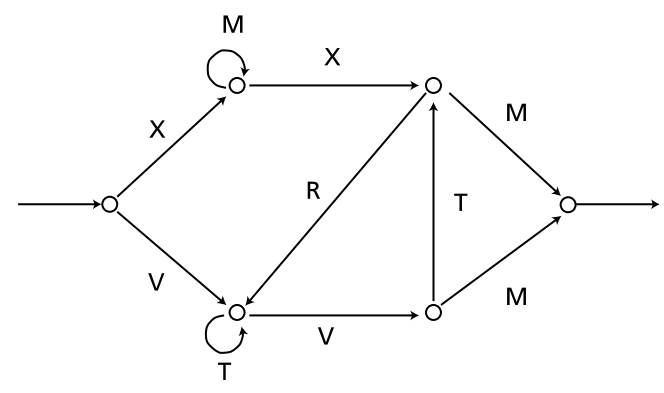

The copies are removed, and a short time later, the subject is asked to look at 60 strings made up of the letters $\mathrm{X}, \mathrm{V}$, $\mathrm{M}, \mathrm{R}, \& \mathrm{~T}, 30$ of which were generated by the original grammar and 30 by a different one. Next, the subject is told that the copied strings have something in common, and is asked to classify these 60 strings, each according to whether it has that same thing in common.

The classification task is a mystery, and coming up with a grammar that corresponds to the original 45 strings requires guessing-abduction. But, any performed abduction takes place implicitly in the subject's mind. This test measures implicit learning - or implicit abduction: what grammar can give rise to the 45 test strings?.

Now consider a modified experiment: suppose a group of 40 people, broken into two 20-person groups, is asked to do the above exercise, but before that, the members of each group are asked to read an illustrated short story. One group reads a revision of Kafka's "The Country Doctor," which is a (slightly) absurdist story; the other group reads a straightforward version of the same story (Proulx \& Heine, 2009b) (see Appendix for a description of the stories). What would happen?

\section{Camus wrote about Kafka:}

In this fundamental ambiguity lies Kafka's secret. These perpetual oscillations between the natural and the extraordinary, the individual and the universal, the tragic and the everyday, the absurd and the logical, are found throughout his work and give it both its resonance and its meaning. (Camus, 1955)

Travis Proulx and Steven J. Heine (2009a) did this experiment, and found that the group that read the absurd version of the story were $26 \%$ more accurate (correctly 
identified strings from the grammar) than the other, and classified 33\% more strings as belonging to the grammar (ignoring whether they were right or wrong). Proulx and Heine claim this latter result is because of increased motivation, but perhaps it's just increased energy.

Though I didn't do the experiment, my interpretation of its results differs from those researchers. The straightforward version of the story is linear and boring. It doesn't require any guesswork to get its "meaning," which in this case is nothing more than its (dull) plot and happy ending. The absurd version is not particularly crazy or surreal, but it does call for lots of abduction to try to make sense of it. Like many surreal and absurdist stories, no abductions work well, and the reader is left with a sense of mystery and strangeness. But the brain is hard at work abducing and becoming defamiliarized. No wonder, then, that a mind open to far-flung connections is able to learn a little more effectively and confidently.

Defamiliarization seems a way to get the brain abducing and hence exploring and discovering. Given this, we can argue that tools for helping creativity need not be secondclass participants but essential partners to making the new really and radically new.

\section{(uy}

Creative work can be experimental, like Robert Boswell's half-known world, or conceptual. Experimental work refers to a method of creation in which the work-the piece created - emerges as the work proceeds. A good way to think of this is to imagine a painter confronting a blank canvas and simply beginning, waiting for what will emerge to come along. Paul Cézanne was such a painter. He did few studies before taking to the canvas. The term "experimental" is, in this context, unrelated to the term "avant-garde," which refers to pushing the boundaries of accepted art. Here it refers to a way of working, an iterative, incremental, and ultimately agile way of working in which the art is revealed as the piece evolves.

Some experimental writers start with a scene or a situation, sometimes just a sense or feeling - and that becomes a novel. The poet Robert Hass says he starts with a phrase, a word, or a line and a gesture, a physical gesture in the air that indicates, for example, a rising energy level or a decline or some more complicated shape-and the result is a poem (Hass, 2008).

Once a draft begins to take shape - a draft of a written piece or paint on the canvas or some shards off the rock or some notes on the guitar-a process of understanding begins. This is the revision process where what has been discovered is examined and the best story / painting / sculpture / composition is created. Sometimes these drafts are in the form of sketches or studies when the medium is not malleable.

Again, Turchi: "Only after discovery can the work be properly structured, can the selection and organization of the significant moments of time take place" (Turchi, 2004). He continues:

If we attempt to map the world of a story before we explore it, we are likely either to (a) prematurely limit our exploration, so as to reduce the amount of material we need to consider, or $(b)$ explore at length but, recognizing the impossibility of taking note of everything, and having no sound basis for choosing what to include, arbitrarily omit entire realms of information. The opportunities are overwhelming. (Turchi, 2004)

Experimental art is the epitome of exploration and discovery. 


\begin{abstract}
Artists who have produced experimental innovations have been motivated by aesthetic criteria: they have aimed at presenting visual perceptions. Their goals are imprecise, so their procedure is tentative and incremental. The im-precision of their goals means that these artists rarely feel they have succeeded, and their careers are consequently often dominated by the pursuit of a single objective. (Galenson, 2007)
\end{abstract}

But not all creators work exclusively in the realm of "stuff"; not all writers write without a plan, without a concept; not all scientists work exclusively from data to hypothesis. Lots of creative work is not the product of unbounded exploration and discovery; lots of work is based on concepts.

In contrast, artists who have made conceptual innovations have been motivated by the desire to communicate specific ideas or emotions. Their goals for a particular work can usually be stated precisely, before its production, either as a desired image or a desired process for the work's execution. Conceptual artists consequently make detailed preparatory sketches of plans for their paintings. (Galenson, 2007)

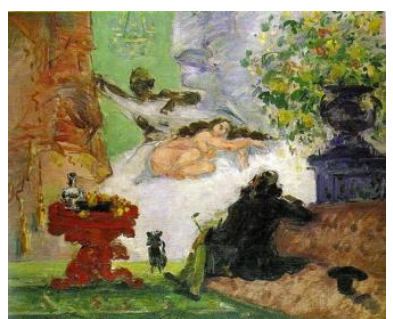

Paul Cézanne: A Modern Olympia

Cézanne, an experimental painter, played. He struggled to develop an authentic observation of the seen world by the most accurate method of representing it in paint that he could find. To this end, he structurally ordered whatever he perceived into simple forms and color planes (abstractions). His artistic goals were things he could only approach and never achieve, and that's why he kept trying, with his best works coming late in life. His

ideas were not concepts that came in a flash, but something he painted and painted and painted. He stalked art, he pursued it like a series pursues its convergence.

Picasso, a conceptual painter, thought of himself as someone from whom art sprung whole. Les Demoiselles d'Avignon is considered by many to be his masterpiece. He carefully planned it. The painting portrays five nude prostitutes in a brothel in Barcelona. The figures are physically jarring, none conventionally feminine, all slightly

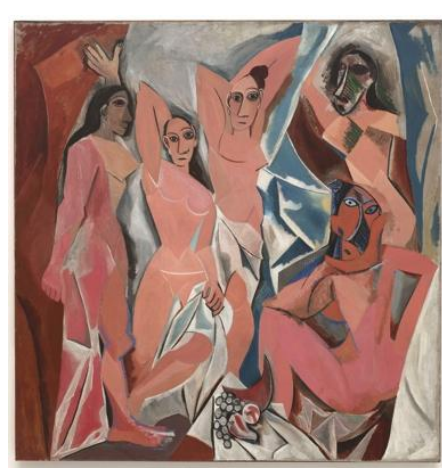
menacing, and each is rendered with an angular and disjointed body shape. Two of the women have Africanmask-like faces, giving them a savage and mysterious aura. This is a variant of Primitivism. Picasso also abandoned perspective to a flat, two-dimensional picture plane.

Picasso stated that his art was the result of what he had found-as opposed to showing his seeking, as Cézanne did-but he claimed to not believe in research.

$$
\begin{aligned}
& \text { I can hardly understand the } \\
& \text { importance given to the word } \\
& \text { "research" in connection with modern } \\
& \text { painting. To find, is the thing.... }
\end{aligned}
$$

When I paint my object is to show what I have found, not what I am looking for.... 
I have never made trials or experiments. Whenever I had something to say, I have said it in the manner in which I have felt it ought to be said. (Picasso, 1923)

Yet, for Les Demoiselles d'Avignon, Picasso did over 400 studies and sketches, a record for artistic preparation. One of those sketches is just to the right. If this isn't playing, experimenting, and researching, I confess to not knowing what those things are. Conceptual artists often behave experimentally - the difference between them and experimental artists is that the experimental artist "plays" with the final piece (modulo revision) while the conceptual artist "plays" with representations, sketches, and studies.

At the top of the next page is a poem

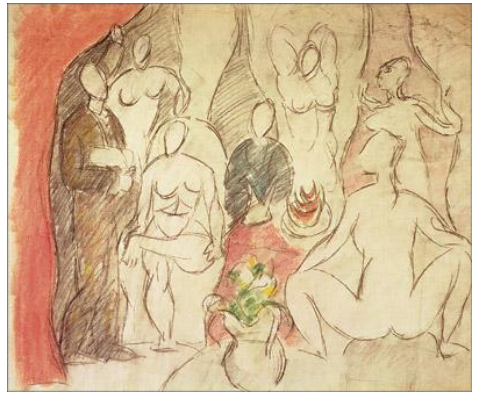
(Stopping by...) I wrote by using Babelfish as a defamiliarization aid. A Robert Frost poem (Frost's original (Frost, 1923) is just below) was run through a number of cycles of translation to and through other languages then back to English to undo the idioms and figures of speech that Frost used originally, producing a set of raw language with which to start to construct a poem - a poem both weirdly similar to the original and dementedly different.

My concept was to use Babelfish to make a set of ridiculous translations of the well-known poem in order to free it of its now-familiar wording. I had it translate the poem from English to Greek, then to Korean, then to Japanese, then to German, and back to English; I used a set of such cyclic translations as the starting point for the poem. This is conceptual art.

\section{Stopping By Woods on a Snowy Evening}

Whose woods these are I think I know.

His house is in the village though;

He will not see me stopping here

To watch his woods fill up with snow.

My little horse must think it queer

To stop without a farmhouse near

Between the woods and frozen lake

The darkest evening of the year.

He gives his harness bells a shake

To ask if there is some mistake.

The only other sound's the sweep

Of easy wind and downy flake.

The woods are lovely, dark and deep.

But I have promises to keep,

And miles to go before I sleep,

And miles to go before I sleep. 


\section{Stopping by http://babelfish.altavista.com on a Snowy Evening}

Here is a task whose outcome is certain:

Thinking of someone's forest

and then thinking whether this forest is that someone's.

And as for his house (I've picked this up):

it is certainly located in town.

I am stopped here paying attention to the snow above, observing the trees filling in above the snow.

My eye finds comfort in this.

As for my horse, he strangely and narrowly stops.

I am small, me and the small end of the tree both agree.

To the horse, we are stopped between a farm and the frozen sea.

This evening is the strangest and the darkest of the year, the horse must think.

His harness bells are his only user interface.

These bells are installed to a flange by some wiring, and so

he gives the flange a shock, vibrating the wires,

thereby jolting the bells (giving them a restlessness)

in order to pose me a question:

Is there some kind of mistake here?

Surely a certain error exists.

$\mathrm{He}$ is a small horse.

There is only one other sound,

a different sound like a clay tone,

but only to the extent of a thin layer or a languid ribbon

forming a closed loop: the sweepback of a light breeze

over downy soft flakes - a simple, easy wind;

flakes like cotton wool or hair

or a rag for cleaning, which is the same thing.

Or maybe it sounds like this:

khlop!

(I am excited by this.)

Woods are attractive. Likable. Lovable, even.

Or sometimes - obscure. One of the trees

is dark and from a place which is deep.

And you know what they say: Dark and deep are deep.

But I am held to obligations which I must maintain.

Before I sleep I must resume my outward journey.

(And other unspecified things of the same class.)

For experimental artists (e.g., painters):

...planning a painting is unimportant. The subject selected might be simply a convenient object of study, and frequently the artist returns to work on a motif he has used in the past. Some experimental painters begin without a specific subject in mind, preferring instead to let the 
subject emerge as they work. Experimental painters rarely make elaborate preparatory sketches. Their most important decisions are made during the working stage. The artist typically alternates between applying paint and examining the emerging image; at each point, how he develops the image depends on his reaction to what he sees. (Galenson, 2007)

For conceptual artists (e.g., painters):

...planning is the most important stage. Before he begins working, the conceptual artist wants to have a clear vision either of the completed work or of the process that will produce it. Conceptual artists consequently often make detailed preparatory sketches or other plans for a painting. With the difficult decisions already made in the planning stage, working and stopping are straightforward. The artist executes the plan and stops when he has completed it.

...extreme practitioners.. make all the decisions for a work before beginning it. It is unclear, however, if this is literally possible. There are artists who came close to it, and perhaps achieved it, during the 1960s, by making plans for their work and having these plans executed by others. (Galenson, 2007)

Both poetry examples I've shown were produced using human effort after or intertwined with machine assistance, and in both cases the success of the result depended on the machine tools being flawed-or simply not very good. Had Google returned synopses of only rational documents mentioning my irrational search terms, I would have no starting point at all; and had Babelfish been a perfect translation engine, the starting point would simply be the original Frost poem. But luckily Babelfish made many trips from English and eventually back again like this trip to Japanese and back:

$$
\begin{aligned}
& \text { The only other sound is the sweep } \rightarrow \quad \text { Only other sound: The extent of the thin layer } \\
& \text { Of easy wind and downy flake. } \rightarrow \quad \text { the easy wind and like the cotton wool. }
\end{aligned}
$$

What I mean by flawed tools being good for creativity can be seen at the top of the next page. This poem was created by first taking one of the stanzas from "The Love Song of J. Alfred Prufrock," by T. S. Eliot, and running it through a sorting algorithm that uses a comparison predicate $(<)$ that lies about $4 \%$ of the time. The result was the first draft of the poem. The sorting is based on the position of the words in the text and not what the words are. Guy Steele also used the idea in some poetry he was writing, and he and I each (independently) discovered the optimality of $4 \%-7 \%$ as the best "degree of lying": larger than this and the result is gibberish, smaller and the result is too similar to the original to trigger new and interesting connections. One way to express this is that were the sorting perfect, the tool would have been useless, but being off by just a little is just enough defamiliarization to, perhaps, optimize creativity. (Note that lying $100 \%$ of the time would simply reverse the poem.) 


\section{Love Song of Lisp}

and would it have been tea

after the cups the marmalade

among the porcelain

talk among some of you and me and the dead

would it have been worthwhile

to have bitten off the matter with a smile

to have squeezed the universe into a come ball

to roll it toward some overwhelming question

say to me I am Lazarus come from the back

to tell you not all / I shall tell you all

if one setting a pillow by her head should say

that is not what I meant at all

that it would be all and it would have been worth it after it

after all it would have been worthwhile after the sunsets

and the streets and the dooryards and sprinkled-after novels

teacups after patterns

the skirts that trail along more of the floor

and this so much is impossible to say just what I mean

but as if I threw a magic lantern

it would be the nerves on a not-setting screen

it would have been worthwhile if one pillow

thrown off or throwing a shawl

would turn toward the window and should say

that this is all and that is not what I meant at all

Defamiliarization seems to work on the principle of inducing the mind to engage in a sensible resolution of a mistake or set of mistakes, which forces an exploration and perhaps a discovery. One might suspect that defamiliarization as a technique for writing poetry was invented in the early $20^{\text {th }}$ century as part of Dadaism or surrealism, but I believe its origins can be traced much earlier to the use of formal meter and rhyme. When one writes experimentally using formal meter and rhyme, the line that comes first to mind typically doesn't fit rhythmically or obey the rhyme scheme; most importantly, the first thing to come to mind is very likely to be idiomatic or to have been heard recently on the street. The first revision might be to try to restate the line to fit the form. However, when this doesn't work, the next move might be to say something else, perhaps something that is not as directly related to what's on the page already, or maybe something a little indirect or oblique. Or maybe even a little strange and related not to the "meaning" or "intention" already in place but to an earlier image or word or phrase. This forces the poet away from the familiar and idiomatic. In other words, the "mistake" that is the mismatch of the meter and rhyme of the first thought to the poem's required strict meter and rhyme scheme forces the poet to explore in order to discover a line that will fit; and this can result in considerable wiggling and drift from the original idea-and in saying something much more interesting than the first things that come to mind. Hence, one can view formal poetry as an early defamiliarization mechanism. When poetry moved away from formalism, other techniques were needed - and were invented.

I have tried to use Google Translate (instead of Babelfish) to make poems the way the Frost derivative was made, but Google Translate generally translates too accurately. More interestingly, using Google to create flarf has similarly become much harder recently. My speculation is that Google's search algorithms have gotten better at trying to locate reasonable documents that satisfy apparently nonsensical search criteria - criteria 
that effectively used to locate crazy documents. I emailed Peter Norvig (2011) about this (Peter is Google's Director of Research). He wrote back:

In the "good old days," Google was closer to a traditional information re-trieval system: if you gave a query that was four unusual words, it would re-trieve only documents that included all four words. Now, we are more aggressive at allowing synonyms and related terms; as you say, we assume the query is sensible and try to make sense of it, rather than doing a literal match to keywords. That is better for most users, but unfortunately not for poets like you.

\section{(uny}

Some scholars have argued that both the ability to reason (properly) and irrationality are products of evolution, but that irrationality is an unfortunate attendant bad side-effect of evolutionary mechanisms. A bug. What if, though, irrationality were our secret doorway to really good abduction, our built-in mechanism to become defamiliarized when the situation requires radical creativity, such as when a unique danger presents itself; maybe evolution discovered that crazy / go nuts has survival value - maybe irrationality is bound to rationality like yin to yang, like resins to hardeners, like Penn to Teller.

\section{References}

Boswell, R. (2008). The half-known world: On writing fiction. Graywolf Press. St. Paul, $\mathrm{MN}$.

Camus, A. (1955). The myth of sisyphus and other essays. J. O'Brien editor and translator. Vintage Books. New York.

Frost, R. (1923). New Hampshire: A poem with notes and grace notes. Henry Holt and Co. New York.

Galenson, D. W. (2007). Old masters and young geniuses: The two lifecycles of artistic creativity. Princeton University Press. Princeton, NJ.

Goldsmith, K. (2009). Flarf is dionysus. Conceptual writing is Apollo. Poetry. Chicago.

Hartshorne, C., \& Weiss, P. (1958). Collected papers of Charles Sanders Peirce, volumes I and II: Principles of philosophy and elements of logic. Harvard University Press. Cambridge, MA.

Hass, R. (2008). Personal communication. Squaw Valley, CA.

Norvig, P. (2011). Re: Search quality question. Personal Communication. 11:42:58AM PDT, June 14, 2011.

Picasso, P. (1923). Picasso speaks. The Arts. New York. May 1923; reprinted in Alfred Barr: Picasso. New York. 1946.

Proulx, T., \& Heine, S. J. (2009a). Connections from Kafka: Exposure to meaning threats improves implicit learning of an artificial grammar. Psychological Science. 20(9), $1125-1131$.

Proulx, T., \& Heine, S. J. (2009b). The country dentist (two versions). Retrieved from http://dreamsongs.com/Files/ImplicitLearningStories.pdf (Reprinted).

Shklovsky, V. B. (1988). Art as technique. In D. Lodge (ed.), Modern criticism and theory: A reader. London: Longman. (pp,15-30).

Stafford, W. (1987). Writing the Australian crawl. University of Michigan Press. Ann Arbor.

Turchi, P. (2004). Maps of the imagination: The writer as cartographer. Trinity University Press. 


\section{Appendix}

The Country Dentist, straightforward: A country dentist is summoned to a distant village to attend a boy with a terrible toothache. A snowstorm is raging, and what's worse: the dentist's horse has escaped the barn and run away. The dentist sends his housekeeper into town to borrow a horse, and she returns with the local postman and his horse. As he gets ready for the trip, the dentist notices that the postman and housekeeper are fond of each other. By now it's getting dark and the trip will be hard. After a long and difficult journey, the dentist arrives and finds that the boy's tooth is badly decayed and needs to be pulled. Some family members are disappointed the dentist isn't able to do more, but soon that's forgotten, the tooth is pulled, and the dentist spends that night in their home. The next morning he has a good meal and returns home to find that his housekeeper and the postman have decided to find a minister to get married right away.

The Country Dentist, absurd: A country dentist is summoned to a distant village to attend a boy with a terrible toothache. A blizzard is raging, and what's worse: the dentist's horse has escaped the barn and run away. The dentist sends his servant girl into town to borrow a horse, but she returns with nothing. The dentist, upset, kicks the door of his abandoned pigsty, and the door opens to reveal a strange, crude man crouched down along with two enormous horses, also crouched down. With some effort the horses emerge, and the crude man and servant girl harness the horses to the carriage. The crude man grabs the girl and kisses her passionately, and the dentist threatens him. The dentist gets in the carriage and the crude man slaps the horses into a gallop. Almost immediately the carriage arrives at the boy's house and the blizzard is over. The dentist enters a disgusting room and goes to the boy, who whispers, "pull my tooth." The two horses push their heads through an open window and watch the dentist; the dentist discovers the boy has no teeth. The dentist thinks about his beautiful servant girl and how she is probably lost to the lust of the crude man. The family begins to cry and the dentist examines the boy again to find he has teeth, and one of them is badly decayed and filled with worms. The family grabs the dentist and carries him to the boy's bed and lays him next to the boy. The dentist lies there thinking of escape and how fast the horses can get him back home. 